\title{
Do Short Message Reminders Improve ART Adherence? Randomized Control Trial among HIV Clients - Kadoma (Zimbabwe) - KAMP Study Protocol
}

\author{
Article by D. Chirundu ${ }^{1}$, S. Tapesana ${ }^{2}$, P.N. Magande ${ }^{3}$, G. Madzingaidzo ${ }^{4}$, T. \\ Mduluza $^{5}$ \\ ${ }^{1,4}$ Health Dept, Kadoma \\ ${ }^{2,3}$ Dept. of Community Medicine, University of Zimbabwe, Zimbabwe \\ ${ }^{5}$ Dept. of Biochemistry, University of Zimbabwe, Zimbabwe \\ E-mail: ${ }^{1} d c h i r u n d u @ m e . c o m,{ }^{2}$ drstanelytaps@gmail.com, ${ }^{3}$ pmagande@gmail.com, \\ ㅁgeshemma08@gmail.com, ${ }^{5}$ tmduluza@medic.ac.zw
}

\begin{abstract}
Background: Adherence to antiretroviral therapy among clients seeking care at Kadoma City Integrated TB and HIV Care Site has been documented to be $86 \%$ as opposed to the expected adherence of 95\%. The Zimbabwe 2015 survey for Early Warning Indicators for HIV drug resistance identified Kadoma as a hotspot. Low level adherence to antiretroviral therapy is associated with poor clinical outcomes. We set out to evaluate the efficacy of cell phone-supported short message reminders compared to standard care on adherence among clients receiving antiretroviral therapy at Kadoma, Zimbabwe.

Methods: The study design is a randomized controlled trial. Patients on ART at Rimuka Integrated TB and HIV Care Site will be randomized to receive either a structured weekly text message in addition to standard care (the intervention) or standard care support alone (the control). Respondents will be evaluated at baseline, six months and 12 months after recruitment into the study. Primary outcomes are self-reported adherence to ART and CD4 cell counts at twelve months scheduled follow-up. Secondary outcomes will be opportunistic infections, weight, body mass index (BMI) and retention on ART. Primary analysis will be by 'intention-to-treat'.

Discussion: The mHealth concept could be an innovative method in prompting adherence to anti-retroviral therapy in poor resource settings. The trial will evaluate the efficacy of a weekly personalized SMS reminder on adherence among clients on ART at Rimuka Integrated Tuberculosis and HIV clinic Kadoma, Zimbabwe.
\end{abstract}

Keywords: Adherence, ART, HIV, Kadoma, SMS, RCT

\section{Introduction}

Human immunodeficiency virus (HIV) continues to be a global public health problem, having claimed more than 39 million lives so far ${ }^{1}$. There were approximately 36.7 million people living with HIV at the end of 2015, with 2.1 million people becoming newly infected with HIV globally. Sub-Saharan Africa is the most affected region, with 25.5 million people living with HIV in 2015. More so, sub-Saharan Africa also accounts for almost 70\% of the global total of new HIV infections. ${ }^{2}$

Antiretroviral (ARV) medications are long-term treatments whose aim is to drive viral load below the current detection limit. Viral suppression in turn reduces immune suppression and slows disease progression. Improvements in access to effective ART has resulted in the clinical and public health benefits; shown by the greatly reduced number of HIV infected people progressing to AIDs and reduced hospital occupancy rates. The age adjusted death rates from HIV/AIDS has drastically declined more than $70 \%$ since the wide accessibility of ART. ${ }^{3,4,5}$

Compliance to ART is critical to the survival of HIV infected people. However, successful antiretroviral treatment is reliant on sustaining high rates of adherence. The optimal level of 
Texila International Journal of Clinical Research

Volume 4, Issue 1, Jun 2017

adherence required for anti- retroviral (ARVs) medication to work effectively is $95 \%{ }^{6,7}$ This level of adherence demands taking the correct dose of drugs at the right time, and observing any dietary restrictions. Anything less than this level of adherence leads to viral resistance and ultimately treatment failure.

Whilst adherence to ART has emerged as a major determinant of the success of antiretroviral therapy, other determinants of antiretroviral therapy outcomes have been documented. ${ }^{8}$ Genetic differences in drug metabolism, severe baseline immune suppression, prior drug resistance and concurrent opportunistic infections have been shown to determine the clinical outcomes of antiretroviral therapy. ${ }^{16}$ Among the determinants of clinical outcomes, adherence to ART is one of the few modifiable factors determining outcomes for patients on ART. ${ }^{9,10,11}$

A number of $m$ Health interventions have been tested in Africa and beyond as a behavioral intervention to improve adherence. In a parallel RCT study in Cameroon 2007,adults 21 years and older clients received weekly standardized motivational text message versus normal care. ${ }^{12}$ The primary outcome was adherence measured as per visual analogue scale (VAS), number of missed doses a week preceding the interview and pharmacy refill data. The follow up period in this study was six months. The study did not demonstrate a significant difference in adherence by VAS and reported missed doses on comparing the intervention and nonintervention groups. It was concluded that standard motivational mobile phone message did not improve adherence. Whist the duration of the study could have been an issue other researchers have reported positive results with fewer respondents.

Two clinical trials in Kenya have evaluated the benefits of using phone text message reminders to improve adherence. The Weltel trial (2009) was a multisite parallel arm RCT that compared SMS and standard care among ART clinic attendees. ${ }^{13}$ Weekly SMSs that were supposed to be responded to in $48 \mathrm{hrs}$ were send to 273 respondents each in the intervention and non-intervention arm. The intervention group had more than 95\% adherence compared to $50 \%$ in the non-intervention group. This study showed that those who received SMS had improved ART adherence and rate of viral suppression compared to controls.

In a factorial design randomized control trial in Kenya 2011. Cristian Pop-Eleches et. al. evaluated the efficacy of SMS reminders against standard care. ${ }^{14}$ In this study, 70 received short messages daily, 72 received long messages daily, 73 received short messages weekly and 74 long messages weekly. It is reported that weekly SMS reminders increased the participant's adherences by $13 \%-16 \%$ thereby achieving a $90 \%$ overall adherence compared to those who did not receive reminders. Pop Eleches et. al. concluded that SMS reminders may be an important tool to achieve optimal adherence to antiretroviral therapy in resource limited settings. The findings by Pop Eleches et. al. were consistent with Maduka et.al. (2012) in Nigeria who found an increased adherence among participants who received SMS reminders compared to the non-interventional group.

There are still many gaps and the quality of some of the trials leaves a lot to be desired. The proposed study will test the efficacy of SMS in an urban setting in Zimbabwe and this is the first time such a study will be done in the country. The results of the study will be used primarily by HIV/AIDS control programs to improve adherence. This will, in turn, have an effect on virological failures, clinical outcomes and ultimately health related quality of life of the infected. The objective of the study is to investigate the efficacy of cell phone short message reminders on adherence to anti-retroviral therapy among clients seeking HIV care at Rimuka Integrated HIV/TB clinic.

\section{Methodology}

\section{Description of study site}

Rimuka Integrated HIV and TB Clinic is the trial setting. This is a primary health care center at Kadoma (Zimbabwe). The center provides HIV and TB collaborative services. It was established in 2012. In terms of HIV workloads in the City, Rimuka has the highest workload of 7300 clients compared to 2600 managed at Kadoma general hospital a 
government referral center. The catchment area for Rimuka Integrated HIV and TB center is primarily Rimuka high density suburb with a population of 52000 .

\section{Study design}

A randomized controlled trial will be conducted to investigate the efficacy of weekly short message service (SMS)reminders on improving adherence to ART. In the intervention group, participants will receive a weekly SMS reminder for the duration of the trial. This will be in addition to the usual care offered to clients. The SMS will comprise of a different motivational message each week. Those randomized into the non-intervention group will receive usual HIV care as prescribed by the Zimbabwe ART guidelines. This comprises of CD4+ cell counts, adherence classes and follow up. ${ }^{16}$

\section{Randomization}

The generation and sequential numbering of the sampling frame will be done by a data capture clerk. Generation of the random numbers will be done by a health information officer. The centre manager will compile a list of the respondents using the randomly generated numbers. Group allocations will be done by a nurse by assigning opaque envelopes sequentially as they appear in the box for those recruited into the study. The procedure for concealment will be as described by Gordon S. Doig. ${ }^{17}$ In this study, there will be no allocation concealment and no blinding as it is neither possible to blind respondents nor investigators. To prevent intervention contamination, one person will be selected from each household. However, due to the increased attention on the respondents - Hawthorne effect cannot be ruled out. ${ }^{31}$ Theconsort diagram is presented in figure 1 .

\section{Outcomes}

The primary outcome will be adherence to ART as measured by a combination of selfreported adherence, pill counts, visual analogue scale (VAS), and pill identification tests (PIT). Adherence will be measured at baseline, six months and 12 months. The secondary outcomes will be Cluster of Differentiation 4+ $(\mathrm{CD} 4+)$ count, viral load, opportunistic infection, weight, and body mass index.

\section{Intervention}

In the intervention group, participants will receive a motivational SMS reminder on a weekly basis for the duration of the trial. This will be in addition to the usual care offered to clients as defined by the Zimbabwe ART guidelines. Motivational messages that will be sent on a weekly basis will include 'Time for your life' and 'Do not forget to take your medication' among others. The message will change on a weekly basis.

\section{Non intervention}

Those randomized into the non-intervention group will receive standard HIV care that comprises of CD4+ cell counts, adherence classes and follow up.

\section{Duration}

The duration of the study will be 52 weeks, with measurement of outcomes at baseline, 26 weeks and 52 weeks.

\section{Sample size}

The sample size calculated using Open Epi Version $3.03 a^{\mathrm{TM}}$ was 306 assuming a 1:1 allocation ratio. The study will be set at $80 \%$ power to yield a statistically significant result using a chi-square test (assuming an intention-to-treat principle for the analysis) at alpha $=$ 0.05/2 (i.e. using Fleiss formula and statistical methods for rates and proportions) with a continuity correction. The sample size calculation is based on the comparison between proportions of patients with adherence rates (measured as percent with adherence $>95 \%$ ). The proportion of respondents in each arm of the study who have more than $95 \%$ adherence will 
Texila International Journal of Clinical Research

Volume 4, Issue 1, Jun 2017

be compared because this is the variable with the largest sample size. A two tailed test will be used and effect in either direction will be interpreted. Assuming an attrition rate of $10 \%$ we intend to enroll 168 participants in the intervention and 168 participants in the control group. $^{18}$

\section{Analysis plan}

The analysis and reporting of the results with follow the CONSORT, Consort e-health and SPIRIT 2013 guidelines. ${ }^{19,20,21,22}$ the process of patient selection and flow throughout the study will be summarized using a flow-diagram, figure 1. Patient demographics and baseline outcome variables (both primary and secondary) will be summarized using descriptive summary measures and expressed as means or medians. The intention-to-treat principle will be used to analyze all outcomes. ${ }^{23}$ We will also use multiple-imputation to handle missing data. ${ }^{24}$ Thet-testwill be used for comparing groups on continuous outcomes and the chisquared test for binary outcomes. All statistical tests will be two-sided and at the $5 \%$ level of significance.

\section{Ethical considerations}

The study will be guided by the Belmont and Helsinki reports. ${ }^{25,26,27}$ the study will be reviewed by an ethical review committee (Zimbabwe Medical Research Council). Participation will be voluntary and participants can withdraw from the study at any time. Written informed consent will be obtained from all participants and confidentiality maintained at all stages of the study. The intervention will be a motivational message that will generally talk about health and medicine so that confidentiality of respondent is not compromised.

\section{Discussion}

Human Immunodeficiency Virus has continued to be a global public health problem. ${ }^{1}$ Low adherence among clients in Kadoma as report by Muringazuva et. al (Year) is a threat the HIV control program in general and ART in particular. The World Health Organization has also prioritized the use of ICT/mhealth in health. ${ }^{28}$ It is against this background that this randomized controlled trial to evaluate the efficacy of weekly SMS on anti-retroviral therapy adherence is being conducted. It is hoped that the study design will provide quality evidence to support or dispute the use of ICT/mHealth among clients on ART in Kadoma.

Elsewhere, Lester et. al. (2009) compared the effectiveness of cell phone supported SMS messaging to standard care, quality of life and retention in an adult population. ${ }^{13}$ Mbuagbawet. al. (2011) in a study in Cameron reported no difference in adherence between the intervention and non-intervention group at three and six months. ${ }^{12}$ In our study, we will be assessing the clinical outcomes for a duration of 12 months at six monthly intervals. Batya et. al. (2014) carried out a combination strategy for enhancing linkages to and return to HIV care among newly diagnosed adults in Mozambique. ${ }^{29}$ Unlike Batya whose study was looking at ART naïve respondents, our study will primarily look at the effect of SMS on adherence among those who have been on ART for at least four weeks. Engle et. al. (2015) in Ghana developed a study protocol with an objective to evaluate mhealth intervention on patient adherence and doing a cost benefit analysis. ${ }^{30}$ However; our study will differ from this as we will not do a cost benefit analysis.

The results of this trial are expected to provide evidence on the effect of mobile phone reminders on adherence to ART in a Zimbabwean primary health care context. The intervention is also expected to improve immunological and virologic outcomes. The results will highlight key implications for other low-income settings in sub-Saharan Africa.

\section{Acknowledgements}

This trial is financially supported by Kadoma City Health Department. 
Texila International Journal of Clinical Research

Volume 4, Issue 1, Jun 2017

The KAMP Study team includes: Gift Scholtz, Stella Manyere, Moffat Habibu, Alfred Maruma, Cecilia Suga, Blessing Banda, Precious Banda, Hamilton Gomba, Pamela Mautsa and Edith Mhike.

\section{References}

[1]. An-Wen Chan SPIRIT 2013 Statement: Defining Standard Protocol Items for Clinical Trials: Ann Intern Med. 2013; 158:200-207.

[2]. An-Wen Chan: SPIRIT 2013 explanation and elaboration: guidance for protocols of clinical trials: BMJ | Research Methods and Reporting 31/01/2013 10:33:37.

[3]. Batya Elul, Maria Lahueta, Fatima Abacassamo, Mattew R lamb, Laurence Ahoua, Margaret L. McNairy, et.al. A combination strategy for enhancing linkage to and retention in HIV care among adults newly diagnosed with HIV in Mozambique: study protocol for a site-randomized implementation science study. BMC Infectious Diseases201414:549).

[4]. Braitstein P; Mortality of HIV-1-infected patients in the first year of antiretroviral therapy: comparison between low-income and high-income countries. Lancet. 2006 Mar 11; 367(9513):817-24.

[5]. Cristian Pop-Eleches, Harsha Thirumurthy, James P. Habyarimana, Joshua G. Zivin, Markus P. Goldstein, Damien de Walque, Leslie MacKeenet al. Mobile phone technologies improve adherence to antiretroviral treatment in a resource-limited setting: a randomized controlled trial of text message reminders: AIDS. 2011 March 27; 25(6): 825-834.

[6]. caled-Up Mobile Phone Intervention for HIV Care and Treatment: Protocol for a Facility Randomized Controlled Trial; Journal of Medical Internet Research 2015.).

[7]. De Costa et al, Anita Shet, Nagalingeswaran Kumarasamy, Per Ashorn, Bo Eriksson, Lennart Bogg, Vinod K. Diwan et. al. Design of a randomized trial to evaluate the influence of mobile phone reminders on adherence to first line antiretroviral treatment in South India - the HIVIND study protocol: BMC Medical Research Methodology 2010, 10:25

[8]. Edward L. Machtinger: Adherence to HIV AntiretroviralTherapy: HIV InSite Knowledge Base Chapter) USCF.(2002)

[9]. Gordon S. Doig and Fiona Simpson: Randomization and allocation concealment: A practical guide for researchers. Journal of Critical Care Close: Block 20.2 (Jun 2005): 187-91

[10]. Government of Zimbabwe Guidelines for Antiretroviral Therapy for the Prevention and Treatment of HIV in Zimbabwe. The National Medicine and Therapeutics Policy Advisory Committee 2013).

[11]. Garrett Mehl and Alain Labrique; Prioritizing integrated mHealth strategies for universal health coverage: Science 345, 1284 (2014))

[12]. Gunther Eysenbach: CONSORT-EHEALTH: Improving and Standardizing Evaluation Reports of Web-based and Mobile Health Interventions J Med Internet Res. 2011 Oct-Dec; 13(4): e126.

[13]. J.A. Lewis' \& D. Machin Intention to treat - who should use ITT? Br. J. Cancer 1993 647-650.

[14]. John G. Adair. The Hawthorne Effect: A Reconsideration of the Methodological Artifact Journal of Applied Psychology1984).

[15]. Kelly L L'Engle, Kimberly Green, Stacey M Succop; Amos Laar, Samuel Wambugu

[16]. Little RJA, Rubin DB: Statistical analysis with missing data. New York: John Wiley \& Sons; 1987

[17]. Mocroft A, et al; Decline in the AIDS and death rates in the Euro SIDA study: an observational study. Lancet. 2003 Jul;362(9377):22-9

[18]. Mbuagbaw L, Thabane L, Ongolo-Zogo P, Lester RT, Mills E, Volmink J, et. al. The Cameroon Mobile Phone SMS (CAMPS) trial: A protocol for a randomized controlled trial of mobile phone text messaging versus usual care for improving adherence to highly active anti-retroviral therapy: Trials 2011, $12: 5$

[19]. Maduka O, Tobin-West CI: Adherence counseling and reminder text messages improve uptake of antiretroviral therapy in a tertiary hospital in Nigeria. Niger J ClinPract 2013; 16: 302-08

[20]. Palella F.J, Delaney K.M, Moorman A.C, Loveless M.O, Fuhrer J, Satten A.G et. al.: Declining morbidity and mortality among patients with advanced human immunodeficiency virus infection. HIV Outpatient Study Investigators. N Engl J Med 1998; 338:853-60. 
Texila International Journal of Clinical Research

Volume 4, Issue 1, Jun 2017

[21]. Paterson DL, Swindells S, Mohr J, Brester M, Vergis EN, Squier C, et al.: Adherence to Protease Inhibitor Therapy and Outcomes in Patients with HIV Infection. Ann Intern Med. 2000;

[22]. Russell S. Pioneering S.F: AIDS ward celebrates its first 20 years. San Francisco Chronicle. San Francisco, July 26, 2003: A-19.

[23]. Reiter G., Stewart K., Bangsberg D. Elements of success in HIV clinical care: Multiple interventions that promote adherence. Topics in HIV Medicine 2000; 8:21-30.

[24]. Rosa Garcia; Robert T. Schooley; Roberto Badaró. An Adherence Trilogy is Essential for Long Term HAART Success: The Brazilian Journal of Infectious Diseases 2003.

[25]. Reiter GS, Stewart KE, Wojtusik L. Elements of success in HIV clinical care: Multiple interventions that promote adherence. Topics in HIV Medicine 2000: 867

[26]. Richard T Lester, Edward J Mills, Antony kariri, paulRitvo, Michael Chung, William jack, james Habyarimana: The HAART cell phone adherence trial WelTel Kenya1): a randomized controlled trial protocol: Trials 2009.

[27]. Schulz KF, Altman DG, Moher D: CONSORT 2010 Statement: Updated guidelines for reporting parallel group randomised trials. J Clin, Epidemiol. 2010, 63:834-840.

[28]. UNAIDS, Aids by numbers. AIDS is not yet over but it can. UNAIDS 2016

[29]. WHO. Global health sector response to HIV, 2000-2015: focus on innovations in Africa: progress report WHO 2015

[30]. University of Minnesota Centre for Bioethics A Guide to Research Ethics: University of Minnesota Centre for Bioethics.

[31]. UNITED STATES. The Belmont report: Ethical Principles and Guidelines for the Protection of Human Subjects of Research: Bethesda, Md. The Commission (1978).

[32]. Williams JR: The Declaration of Helsinki and Public health: Bulletin of the World Health Organization 2008; 86: 650-651. 
Texila International Journal of Clinical Research

Volume 4, Issue 1, Jun 2017

\section{KAMPS consort diagram}

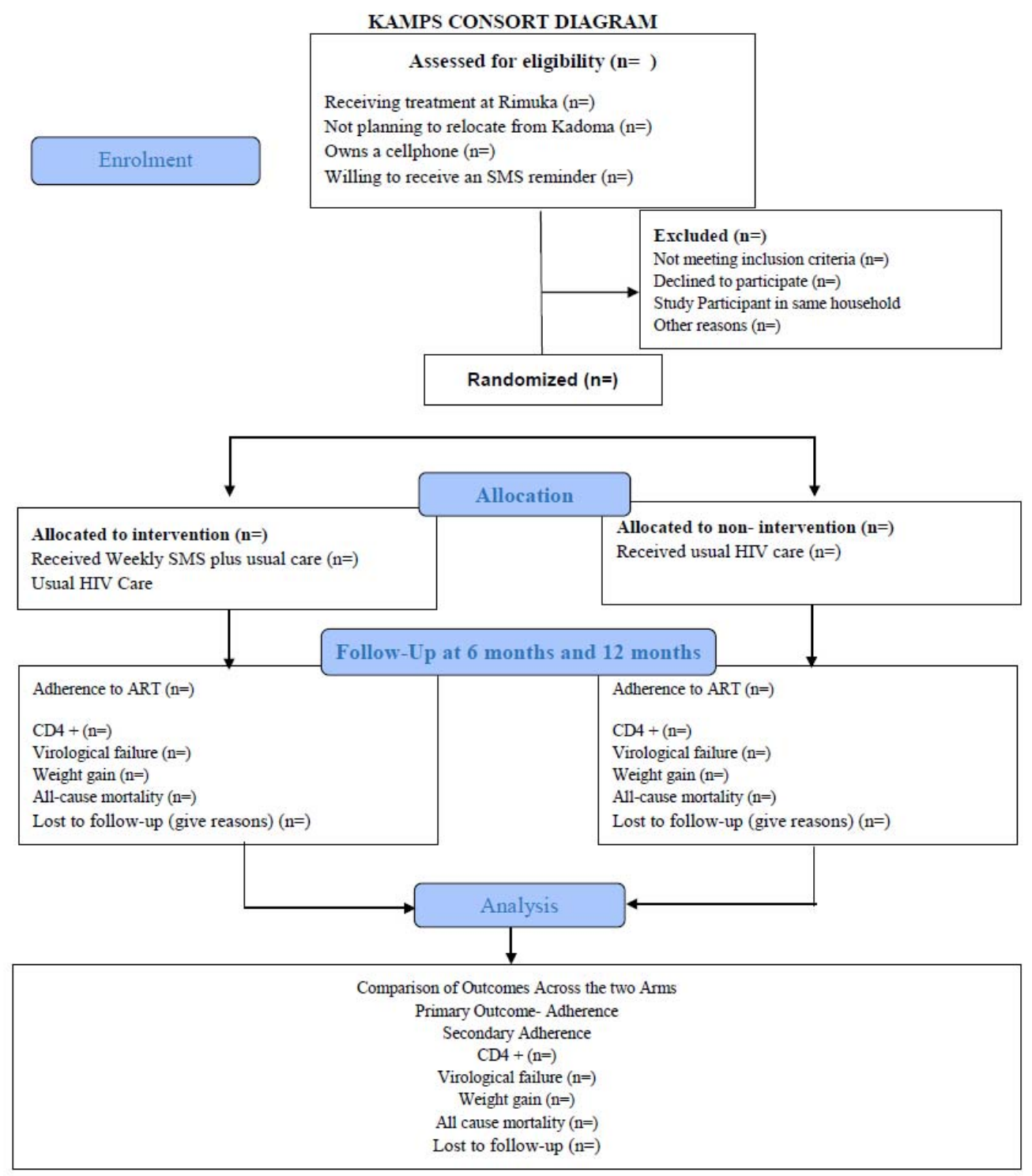

Figure 1. KAMPS Study Consort Diagram 
Texila International Journal of Clinical Research

Volume 4, Issue 1, Jun 2017

Table 1.Plan for Data Analysis

\begin{tabular}{|c|c|c|c|}
\hline $\begin{array}{l}\text { Variable } \\
\text { Outcome }\end{array}$ & Hypothesis & $\begin{array}{l}\text { Outcome } \\
\text { Measure }\end{array}$ & Method of Analysis \\
\hline Primary & $\begin{array}{l}\text { Intervention } \\
\text { improved } \\
\text { outcome from } \\
\text { baseline to } \\
\text { 6months }\end{array}$ & & \\
\hline $\begin{array}{l}\text { Adherence to } \\
\text { ART at } 6 \text { months }\end{array}$ & & $\begin{array}{l}\text { Percentage } \\
\text { adherence in } \\
\text { previous } \\
\text { 30days }>95 \% \\
\text { [binary] }\end{array}$ & Chi-squared \\
\hline Secondary & $\begin{array}{l}\text { Improvement } \\
\text { occurred }\end{array}$ & & \\
\hline $\begin{array}{l}\text { Adherence \% at } \\
12 \text { months }\end{array}$ & $\begin{array}{l}\text { Improvement } \\
\text { occurred }\end{array}$ & & \\
\hline $\begin{array}{l}\text { Immune } \\
\text { reconstitution at } \\
6 \text { months }\end{array}$ & $\begin{array}{l}\text { Improvement } \\
\text { occurred }\end{array}$ & $\begin{array}{l}\text { CD4 T- } \\
\text { cells/mm3 } \\
\text { (continuous) }\end{array}$ & T-test \\
\hline $\begin{array}{l}\text { Weight gain and } \\
\text { BMI }\end{array}$ & $\begin{array}{l}\text { Improvement } \\
\text { occurred }\end{array}$ & $\begin{array}{l}\text { Change in } \\
\text { Weight } \\
\text { (continuous) }\end{array}$ & T-test \\
\hline $\begin{array}{l}\text { Occurrence of } \\
\text { Opportunistic } \\
\text { Infections }\end{array}$ & $\begin{array}{l}\text { Improvement } \\
\text { occurred }\end{array}$ & $\begin{array}{l}\text { Presence of } \\
\text { AIDS defining } \\
\text { opportunistic } \\
\text { infection (binary) }\end{array}$ & Chi-square \\
\hline Deaths (all cause) & $\begin{array}{l}\text { Improvement } \\
\text { occurred }\end{array}$ & $\begin{array}{l}\text { All-cause } \\
\text { mortality (binary) }\end{array}$ & \\
\hline Rand 360 & $\begin{array}{l}\text { Improvement } \\
\text { occurred }\end{array}$ & $\begin{array}{l}\text { Quality of life } \\
\text { questionnaire }\end{array}$ & T-test \\
\hline $\begin{array}{l}\text { Satisfaction with } \\
\text { Care provided }\end{array}$ & $\begin{array}{l}\text { Improvement } \\
\text { occurred }\end{array}$ & Questionnaire & \\
\hline $\begin{array}{l}\text { Level of } \\
\text { Disclosure HIV } \\
\text { Status }\end{array}$ & $\begin{array}{l}\text { Improvement } \\
\text { occurred }\end{array}$ & Questionnaire & Chi-square \\
\hline $\begin{array}{l}\text { Impression of } \\
\text { Stigma }\end{array}$ & $\begin{array}{l}\text { Improvement } \\
\text { occurred }\end{array}$ & Questionnaire & T-test \\
\hline Family Dynamics & $\begin{array}{l}\text { Improvement } \\
\text { occurred }\end{array}$ & Questionnaire & T-test \\
\hline $\begin{array}{l}\text { Variable } \\
\text { Outcome }\end{array}$ & Hypothesis & $\begin{array}{l}\text { Outcome } \\
\text { Measure }\end{array}$ & Method of Analysis \\
\hline $\begin{array}{l}\text { Cellphones /lost } \\
\text { Stolen }\end{array}$ & $\begin{array}{l}\text { Improvement } \\
\text { occurred }\end{array}$ & $\begin{array}{l}\text { Presence of } \\
\text { cellphone }\end{array}$ & T-test \\
\hline $\begin{array}{l}\text { Stopped Taking } \\
\text { ART }\end{array}$ & $\begin{array}{l}\text { Improvement } \\
\text { occurred }\end{array}$ & Self-report & T-test \\
\hline $\begin{array}{l}\text { Required Active } \\
\text { tracing } \\
\text { Subgroup } \\
\text { Analysis }\end{array}$ & $\begin{array}{l}\text { Improvement } \\
\text { occurred }\end{array}$ & $\begin{array}{l}\text { Field officer } \\
\text { binary }\end{array}$ & Chi-square test \\
\hline Female Vs. Male & \multicolumn{3}{|l|}{$\begin{array}{l}\text { Sex (gender affects } \\
\text { adherence) }\end{array}$} \\
\hline Area of Residents & Distance to HC & & \\
\hline
\end{tabular}


Texila International Journal of Clinical Research

Volume 4, Issue 1, Jun 2017

Level of

affects adherence

Education

Low education

Employed vs.

affects adherence

unemployed

Employment status

affects adherence

4. Sensitivity

Improvement occurs

Analysis

Per protocol

analysis

Adjusting for

baseline

Chi-square /T test

Clustering

Multivariate

analysis 